\section{Krahn Chemie distributes emulsions manufactured by Celanese Emulsions}

Erom rom 1 June 2013 onwards, Krahn Chemie GmbH will act as the German ufactured by Celanese Emulsions $\mathrm{GmbH}$.

The emulsion products, which are sold under the brand names Mowilith and Vinamul, are based on vinyl acetate/ethylene (VAE), vinyl acetate copolymers, acrylics and styrene acrylics. The products can be used in a wide range of applications. For example, in the paint and coatings industries, these aqueous binders are used for facade coatings and interior emulsion paints, as well as for other industrial applications. They are also used in the construction chemicals and adhesive industries.

Krahn Chemie has been working with Celanese EVA Performance Polymers on the distribution of EVA copolymers since 2010.

\section{Progress on the construction of the TDI plant in Dormagen}

$T_{\text {uemeng }}^{\text {he }}$ he new production facility for toluene diisocyanate (TDI) was first announced by Bayer MaterialScience in 2008. Construction work began at the Chempark Dormagen site in the spring of 2012 and has just reached an important phase. Six extremely large components have been transported to the construction site and put in posi-

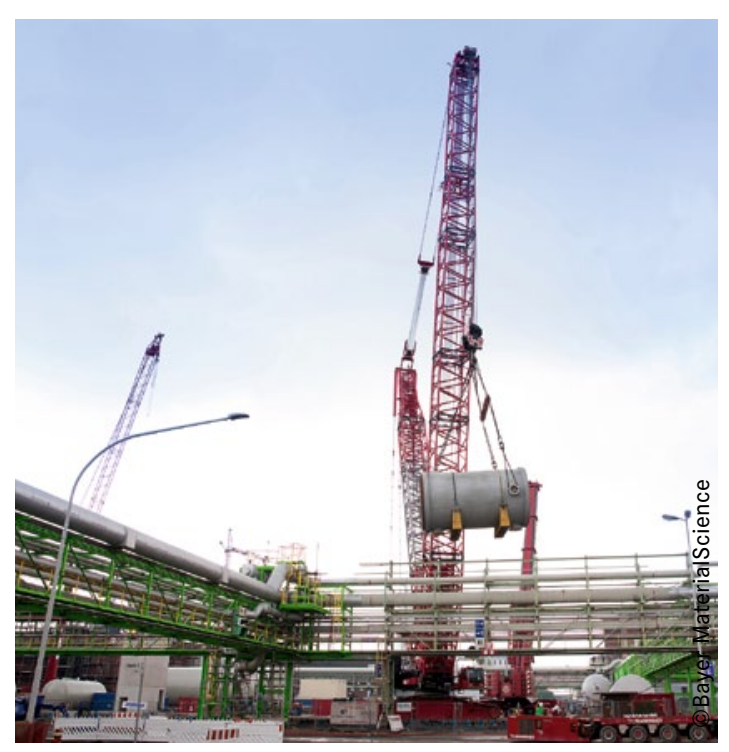

tion. This included the heaviest component of the new plant, which weighed almost 170 tonnes. A special tracked crane was needed to position the heavy components. The individual parts of the crane were delivered on 35 trucks. Work is also going ahead at full speed in other areas of the Dormagen site. Several hundred workers are currently involved in the construction of the large-scale TDI facility, with the aim of ensuring that production can begin next year. The most obvious progress has been made on the steel frame of the new plant, which has already reached a height of around 50 metres. Less noticeable, but equally important, is the installation of the piping systems, for example. Work on assembling more than 60 kilometres of pipes has already begun.

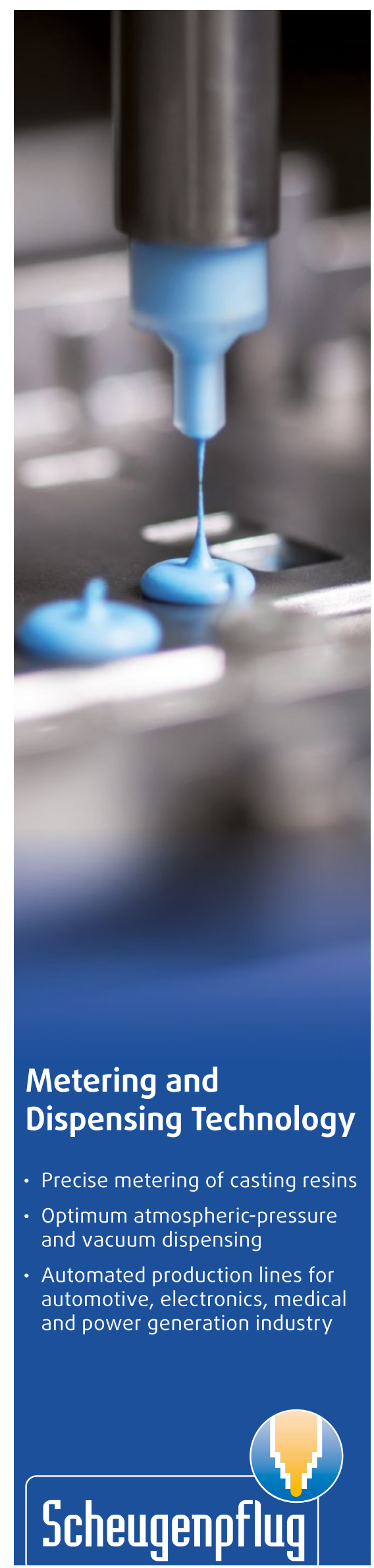

